\title{
The detection of age-, gender-, and region-specific changes in mouse brain tocopherol levels via the application of different validated HPLC methods
}

Authors: Nikolett Nánási ${ }^{1}$, Gábor Veres ${ }^{1,2}$, Edina K. Cseh $^{1}$, Márton Szentirmai ${ }^{1}$, Diána Martos ${ }^{1}$, Evelin Sümegi ${ }^{1}$, Levente Hadady ${ }^{1}$, Péter Klivényi ${ }^{1}$, László Vécsei ${ }^{1,2}$, Dénes Zádori ${ }^{1 *}$

\section{Affiliations:}

${ }^{1}$ Department of Neurology, Faculty of Medicine, Albert Szent-Györgyi Clinical Center, University of Szeged, Szeged, Hungary

${ }^{2}$ MTA-SZTE Neuroscience Research Group, Szeged, Hungary

*Corresponding author:

Dénes Zádori MD, PhD

Department of Neurology, Faculty of Medicine, Albert Szent-Györgyi Clinical Center, University of Szeged

Semmelweis u. 6, H-6725 Szeged, Hungary

Phone: +36 62545351

Fax: +36 62545597

E-mail: zadori.denes@med.u-szeged.hu 


\begin{abstract}
The aging process clearly increases the demand for antioxidant protection, especially in the brain, involving that provided by $\alpha$-tocopherol $(\alpha \mathrm{T})$. However, little is known about the age-related changes in brain $\alpha \mathrm{T}$ levels and the influencing effect of gender on it, in human or murine samples as well. Accordingly, the aim of the current study was to detect age-, gender- and region-specific changes in $\alpha \mathrm{T}$ concentrations in mouse brain tissue and to assess the influencing effect of plasma $\alpha \mathrm{T}$ levels on it.

Female and male C57BL/6 mice at the ages of 6, 16 and 66 weeks ( $n=9$ in each group) were applied. $\alpha \mathrm{T}$ levels were determined with high performance liquid chromatography (HPLC) from the striatum, cortex, hippocampus, cerebellum, brainstem and from plasma samples. A detailed validation process was carried out for the applied HPLC method as well.

The results demonstrated that brain $\alpha \mathrm{T}$ levels significantly increased in the striatum, cortex, and hippocampus with aging in both genders, but in a more pronounced way in females with an increasing magnitude of this difference. In case of the cerebellum, a moderate elevation could be detected only in females, whereas in case of the brainstem there was no significant change in $\alpha \mathrm{T}$ level. With regard to plasma samples, no clear trend could be identified.

The current study is the first to present age-dependent gender-specific changes in $\alpha \mathrm{T}$ level in certain brain regions of the $\mathrm{C} 57 \mathrm{Bl} / 6$ mouse strain, and may provide meaningful information for future therapeutic studies targeting aging-related processes.
\end{abstract}

Keywords: tocopherol, mouse, brain, gender, HPLC, aging 


\section{Introduction}

Tocopherols and tocotrienols, also known as the fat-soluble vitamin E, have an outstanding role in antioxidant mechanisms [1,2]. This antioxidant protection may have a special relevance with regard to the brain, which organ is especially prone to oxidative injuries due to its high energy demand and elevated lipid content [3]. Accordingly, the deficiency of vitamin E often causes neurological symptoms and studies have proved significantly lower serum or plasma $\alpha$-tocopherol levels in some neurological disorders, such as in Alzheimer's disease (AD) $[4,5]$ and in Parkinson's disease (PD) [6], which have an increasing prevalence in the elderly, and in some other neurological conditions [7-11].

With regard to the effects of normal aging on serum tocopherol levels, studies have shown a trend of similarly increasing concentrations in both gender $[12,13]$ which may be the consequence of the age-related alteration in lipid homeostasis [14]. Studies investigated $\alpha$-tocopherol $(\alpha \mathrm{T})$ level in cerebrospinal fluid (CSF) in healthy subjects [15] and in patients with Alzheimer-type dementia (ATD) [16] as well. In addition to the delineation of positive correlations between serum and CSF $\alpha \mathrm{T}$ and $\gamma$-tocopherol $(\gamma \mathrm{T})$ levels in the healthy ones, significantly decreased CSF $\alpha \mathrm{T}$ level was demonstrated in ATD compared to controls. In relation to human brain tocopherol levels, studies provided contradictory results. Craft et al. [17] carried out an examination on the regional distribution of the level of $\alpha \mathrm{T}$ and $\gamma \mathrm{T}$ isomers, demonstrating significant age-related (67-90 years, $\mathrm{n}$ $=5-2$ females and 3 males) decline in $\alpha \mathrm{T}$ level, more pronounced in females, but due to low case number, statistical comparison could not be carried out. With regard to the regional distribution, there were no significant differences between the grey and white matter of frontal and occipital cortices. Later, Johnson et al. [18] demonstrated a significant relationship between cognitive functions and tocopherol levels in the serum, cerebellar, frontal, occipital, and temporal cortices of healthy octogenarians and centenarians. In case of serum samples, dramatically lower concentrations were measured, whereas for given brain regions, significantly higher levels were determined with aging. There was a significantly negative correlation between serum and brain $\alpha \mathrm{T}$ levels, except the cerebellum, although cerebellar $\alpha \mathrm{T}$ level, similarly to that of the other brain regions, also positively correlated with the scores of Mini-Mental State Examination (MMSE) and Severe Impairment Battery (SIB), both of which are measures of global cognition.

With regard to rodent studies on tocopherol homeostasis, only limited data are available about the effect of aging and gender on plasma or serum and brain tocopherol levels. Most of the available rodent tocopherol studies did not separate animals to the necessary groups for later statistical comparisons [19-26]. Although Gohil et al. [27] determined $\alpha \mathrm{T}$ level in several brain regions 
(cerebral cortex, hippocampus, cerebellum, midbrain and the remaining part of the brainstem) of 5 months old C57Bl/6 female $(\mathrm{n}=5)$ and male $(\mathrm{n}=3)$ mice and found significantly higher $\alpha \mathrm{T}$ concentrations in all the five regions in females than in males, moreover significantly lower $\alpha \mathrm{T}$ level was observed in the cerebellum than those of other examined brain regions, no information was obtained about the effect of aging. With regard to cholesterol levels, there was not any significant difference between genders. There is only one study [28] which assessed the effect of aging on tocopherol levels of rodents in details and reported a not significant decrease in plasma $\alpha \mathrm{T}$ level (from $\sim 8$ to $\sim 6 \mu \mathrm{M}$ ) with aging in $\mathrm{C} 57 \mathrm{Bl} / 6 \mathrm{NCr}$ male mice $(3,6,12,18$ and 24 months old, $\mathrm{n}$ $=5$ ) and significantly increasing values only in some brain regions (cerebrum (from 10 to 20 $\mathrm{nmol} / \mathrm{g}$ tissue), hippocampus (from 12 to $25 \mathrm{nmol} / \mathrm{g}$ tissue) and cerebellum (from 11 to $15 \mathrm{nmol} / \mathrm{g}$ tissue)). In addition, it was also demonstrated that triglyceride levels were not influenced by aging. However, female mice were not utilized in this study, so the effect of gender cannot be assessed.

There are many available detection methods for the measurement of tocopherol concentrations from plasma or serum and from brain samples [29]. Accordingly, Vitamin E compounds are mainly assessed by diode-array detector (DAD) [30], electrochemical detector (ECD) [31], fluorescence detector (FLD) [32] or mass spectrometry [22, 33]. In case of plasma or serum and brain samples of rodents, especially those of mice, the measurements of other tocopherols are challenging because of their small concentration levels. For the determination of their levels, more sensitive methods are necessary, because with the application of ECD, FLD and DAD, usually only $\alpha \mathrm{T}$ can be measured reliably [29].

The aim of the current study was the expansion of the research of Takahashi et. al. [28] and Gohil et. al [27] to be able to quickly and reliably determine $\alpha$ T concentrations in mouse plasma and brain tissues searching for the influencing effects of gender and aging via the application of robust, reproducible and validated HPLC methods. As a part of this process, the applicability of FLD and ECD detectors for the measurement of $\alpha \mathrm{T}$ from brain samples was investigated as well.

\section{Materials and methods}

\subsection{Materials}

$\alpha \mathrm{T}$, ammonium acetate, ascorbic acid, butylated hydroxytoluene (BHT), dioxane, n-hexane, methanol $(\mathrm{MeOH})$, ethylenediaminetetraacetic acid (EDTA) and sodium-perchlorate $\left(\mathrm{NaClO}_{4}\right)$ were purchased from Sigma-Aldrich (Saint Louis, MO, USA). Rac-tocol (rT) was acquired from Matreya LLC (Pleasant Gap, PA, USA). 
Acetonitrile (ACN), tetrahydrofuran (THF), absolute ethanol (EtOH), isopropanol (IPA), sodiumchloride $(\mathrm{NaCl})$, disodium-hydrogen-phosphate hydrate $\left(\mathrm{Na}_{2} \mathrm{HPO}_{4} * 2 \mathrm{H}_{2} \mathrm{O}\right)$ and sodium-hydrogencarbonate $\left(\mathrm{NaHCO}_{3}\right)$ were purchased from VWR International (Radnar, PA, USA).

Potassium-dihydrogen-phosphate $\left(\mathrm{KH}_{2} \mathrm{PO}_{4}\right)$, sodium-dihydrogen-phosphate $\left(\mathrm{NaH}_{2} \mathrm{PO}_{4}\right)$, D-glucose hydrate (D-glucose*1 $\left.\mathrm{H}_{2} \mathrm{O}\right)$ and calcium-chloride hydrate $\left(\mathrm{CaCl}_{2} * 2 \mathrm{H}_{2} \mathrm{O}\right)$ were obtained from Reanal (Budapest, Hungary).

Potassium-chloride $(\mathrm{KCl})$ and Triton-X were purchased from Spektrum 3D (Budapest, Hungary, from 2008: part of VWR), disodium-sulfate $\left(\mathrm{Na}_{2} \mathrm{SO}_{4}\right)$ from Fine Chemical Co. (Budapest, Hungary) and magnesium-chloride hydrate $\left(\mathrm{MgCl}_{2} * 6 \mathrm{H}_{2} \mathrm{O}\right)$ from Scharlau (Barcelona, Spain).

\subsection{Animals}

For this study C57B1/6 female and male mice were used. The animals were housed under standard laboratory conditions $\left(50 \% \pm 2 \%\right.$ humidity, $22^{\circ} \mathrm{C} \pm 1{ }^{\circ} \mathrm{C}$ temperature range and $12 \mathrm{~h}-12 \mathrm{~h}$ light dark cycle) in cages (max 4 per cage) with free access to food (standard rodent diet) and drinking water. We examined 6 groups of animals consisting of 6, 16 and 66 weeks old male and female mice ( $\mathrm{n}=9$ in each group). All animal experiments were carried out in accordance with the Scientific Ethics Committee for Animal Research of the Protection of Animals Advisory Board (XXIV./352/2012.).

\subsection{Sample preparation}

At the age of 6, 16 and 66 weeks, the animals were deeply anesthetized with isoflurane (Forane ${ }^{\circledR}$; Abott Laboratories Hungary Ltd., Budapest, Hungary). After thoracotomy, venous blood was collected from the right ventricle by intracardial puncture into Eppendorf tubes containing EDTA, followed by perfusion with artificial cerebrospinal fluid $(\mathrm{pH}=7.4$, composition in $\mathrm{mM}$ : $122 \mathrm{NaCl}$, $3 \mathrm{KCl}, 1 \mathrm{Na}_{2} \mathrm{SO}_{4}, 1.25 \mathrm{KH}_{2} \mathrm{PO}_{4}, 10$ D-glucose $* 1 \mathrm{H}_{2} \mathrm{O}, 1 \mathrm{MgCl}_{2} * 6 \mathrm{H}_{2} \mathrm{O}, 2 \mathrm{CaCl}_{2} * 2 \mathrm{H}_{2} \mathrm{O}, 6$ $\mathrm{NaHCO}_{3}$ ) for $5 \mathrm{~min}$ by an automatic peristaltic pump. After centrifugation of blood samples at $4{ }^{\circ} \mathrm{C}$ for 5 min at $3500 \mathrm{RPM}$, the supernatant plasma $(200 \mu \mathrm{L})$ were mixed immediately with $200 \mu \mathrm{L} 85$ $\mathrm{mM}$ ascorbic acid and $400 \mu \mathrm{L} 1.14 \mathrm{mM}$ BHT-EtOH solution and the samples were stored at $-80^{\circ} \mathrm{C}$ until further use. Before measurements, $600 \mu \mathrm{L}$-hexane containing $1.14 \mathrm{mM}$ BHT and rT, as internal standard (IS), was added to the stabilized and freshly thawed plasma samples. After an intensive 1 minute long vortex, the samples were centrifuged at $4^{\circ} \mathrm{C}$ for $10 \mathrm{~min}$ at $12000 \mathrm{RPM}$. In the next step, $450 \mu \mathrm{L}$ of the hexane layer was evaporated under nitrogen flow. The residue was resolved with $75 \mu \mathrm{L}$ ACN and $50 \mu \mathrm{L}$ EtOH-dioxane (1:1), then placed into amber-coloured HPLC vials for measurements. 
The anatomical borders of 5 different brain regions (striatum, cortex, hippocampus, cerebellum and brainstem) were determined with the aid of the online-available Allen Brain Atlas: Mouse Brain (Allen Institute for Brain Science, Seattle, WA, USA; http://mouse.brain-map.org/static/atlas), and they were rapidly removed on ice and stored at $-80^{\circ} \mathrm{C}$ until further use. Before measurements, the samples were weighed and sonicated (UP100H, Hielscher Ultrasound Technology, Germany; amplitude: $100 \%$, cycle: 0.5 ) in $1020 \mu \mathrm{L}$ ice-cold solution (composition in mM: $75 \mathrm{Na}_{2} \mathrm{HPO}_{4} * 2$ $\mathrm{H}_{2} \mathrm{O}, 17 \mathrm{NaH}_{2} \mathrm{PO}_{4}, 121 \mathrm{NaCl}, 2 \mathrm{KCl}, 1$ EDTA, 67 ascorbic acid, 2 BHT and $0.2 \mathrm{v} / \mathrm{v} \%$ Triton-X, 9.8 $\mathrm{v} / \mathrm{v} \% \mathrm{EtOH})$. The samples were centrifuged next at $4^{\circ} \mathrm{C}$ for $10 \mathrm{~min}$ at $12000 \mathrm{RPM}$, and the supernatants were collected and stabilized applying the same method as described in case of the plasma.

\subsection{Chromatographic conditions}

The concentrations of the $\beta / \gamma \mathrm{T}$ and $\delta \mathrm{T}$ were under the limit of detection in cases of all measurements with all the applied detectors, only $\alpha \mathrm{T}$ levels could be quantified, so we focus on this compound in the following part of the methodological description. For the quantification of $\alpha \mathrm{T}$ and the IS (rT) from the mouse plasma samples, a previously published method of the authors was utilized [12], with the slight modification that the chromatographic separations were performed on a Kinetex C18 column, $150 \times 4.6 \mathrm{~mm}$ i.d., $5 \mu \mathrm{m}$ particle size (Phenomenex Inc.,Torrance, CA, USA ).

Two independent methods, utilizing ECD and FLD, were developed for the quantification of $\alpha \mathrm{T}$ from certain different brain regions, also with the application of rT as an IS. Both methods involved the utilization of an Agilent 1100 HPLC system (Agilent Technologies, Santa Clara, CA, USA) equipped with a Model 105 ECD (Precision Instruments, Marseille, France) and a FLD (Agilent Technologies, Santa Clara, CA, USA). Measurements were carried out under isocratic conditions.

The first step of our ECD method development was the determination of the optimal working potential for $\alpha \mathrm{T}$ and rT. As a result of our measurements (Fig. 1) the working potential was set at $+700 \mathrm{mV}$, using a glassy carbon electrode and an $\mathrm{Ag} / \mathrm{AgCl}$ reference electrode.

The mobile phase consisted of $91.25 \mathrm{v} / \mathrm{v} \% \mathrm{MeOH}, 4.25 \mathrm{v} / \mathrm{v} \%$ distilled water, $4.5 \mathrm{v} / \mathrm{v} \%$ IPA and $2.81 \mathrm{w} / \mathrm{v} \% \mathrm{NaClO}_{4}$ and it was delivered at a rate of $1.2 \mathrm{ml} / \mathrm{min}$ at $25^{\circ} \mathrm{C}$ onto the reversed-phase column (Luna C18, 75 x 4.6 mm, $3 \mu \mathrm{m}$ particle size, Phenomenex Inc., Torrance, CA, USA) after passage through a pre-column (SecurityGuard, 4 x $3.0 \mathrm{~mm}$ i.d., Phenomenex Inc., Torrance, CA, USA). $10 \mu \mathrm{L}$ of aliquots were injected by the autosampler with the cooling module set at $4{ }^{\circ} \mathrm{C}$.

For the method, using FLD detection, the mobile phase consisted of pure methanol, applying the slightly modified method of Yuan et al. [34]. The flow rate was $1.8 \mathrm{ml} / \mathrm{min}$ at $25^{\circ} \mathrm{C}$, using the same column as in the ECD method. The excitation and emission wavelengths were set at $292 \mathrm{~nm}$ and 
$330 \mathrm{~nm}$, respectively, for the determination of both $\alpha \mathrm{T}$ and $\mathrm{rT}$ based on spectral analysis. The injection volume was $10 \mu \mathrm{L}$, and the samples were thermostated at $4^{\circ} \mathrm{C}$. For ECD and FLD, 2 parallel measurements were carried out for each sample.

2.5. Validation of the applied methods

2.5.1. Calibration curve and linearity

In case of DAD measurements, calibrators were prepared in $1.14 \mathrm{mM} \mathrm{BHT-EtOH}$, then they were arranged in six different concentration levels with concentration ranges of $1-50 \mu \mathrm{M}$ and $0.25-$ $12.5 \mu \mathrm{M}$ for $\alpha \mathrm{T}$ and $\mathrm{rT}$, respectively. In case of ECD measurements, these ranges were the following: $0.05-2.0 \mu \mathrm{M}$ and $0.30-6.0 \mu \mathrm{M}$ for $\alpha \mathrm{T}$ and $\mathrm{rT}$, respectively, whereas in case of FLD measurements, the concentration levels were similarly between $0.10-2.0 \mu \mathrm{M}$ and $0.30-6.0 \mu \mathrm{M}$ for $\alpha \mathrm{T}$ and $\mathrm{rT}$, respectively. The peak area responses were plotted as a function of the corresponding concentration and linear regression computations were evaluated by the least square method with the freely available $R$ software [35]. Good linearity $\left(R^{2} \geq 0.99\right)$ was detected in each method throughout the concentration ranges for all compounds.

\subsubsection{Selectivity}

To analyze the selectivity of the methods, we matched the chromatograms of $\alpha \mathrm{T}$ and $\mathrm{rT}$ for a blank plasma or central nervous system (CNS) sample and those for a spiked sample. As shown in Fig. 2, both compounds can be detected without interference from other compounds.

\subsubsection{Precision}

With regard to the within-run precision, the coefficients of variation of the concentrations were $0.73 \%, 1.49 \%$ and $3.46 \%$ for $\alpha \mathrm{T}$ and $0.62 \%, 1.84 \%$ and $0.75 \%$ for $\mathrm{rT}$ in case of DAD, ECD and FLD, respectively.

\subsubsection{Recovery}

The relative recoveries were estimated by measuring spiked samples of $\alpha \mathrm{T}$ at two different concentration levels with three replicates of each. No significant differences were observed for the lower and higher concentrations. The recoveries for the plasma samples ranged from $67 \%$ to $71 \%$ with $\mathrm{DAD}$, whereas the recoveries for brain samples ranged from $104 \%$ to $106 \%$ in case of ECD and $87 \%$ to $104 \%$ with FLD.

2.5.5. Limit of detection (LOD) and limit of quantification (LOQ) 
Regarding the quantitative analysis, both LOD and LOQ are important parameters, LOD showing the smallest concentration that can be detected, but not necessarily quantified, whereas LOQ is the lowest analyte concentration in a sample that can be measured with an acceptable level of accuracy and precision $[36,37]$. In the current study, LOD and LOQ were calculated as shown in Equation 1. The LOD values for $\alpha$ T were the following: $397 \mathrm{nM}, 26 \mathrm{nM}$ and $41 \mathrm{nM}$ for DAD, ECD and FLD, respectively. The LOQ values for $\alpha \mathrm{T}$ were $1202 \mathrm{nM}, 77 \mathrm{nM}$ and $123 \mathrm{nM}$ for DAD, ECD and FLD, respectively.

$$
\text { LOD }=3.3 * \frac{\sigma}{\mathrm{S}^{\prime}} \text { and LOQ }=10 * \frac{\sigma}{\mathrm{S}^{\prime}}
$$

\section{Equation 1}

The calculation of LOD and LOQ values by formula, where $\sigma$ is the standard error of the intercept and $\mathrm{S}^{\prime}$ is the slope of the calibration curve of the analyte. $L O D$ limit of detection; $L O Q$ limit of quantification.

\subsubsection{Statistical analysis}

All statistical calculations were performed with the use of the freely available R software [35]. We first checked the distribution of data populations with the Shapiro-Wilk test, and we also performed the Levene test to confirm the homogeneity of variances. As the distribution proved to be Gaussian and the variances were equal, two-way ANOVA was applied with Tukey HSD post hoc test for pairwise comparison. We decided a priori that the comparisons of opposite gender and age groups may not yield meaningful information, so they were not implemented, therefore only 9 comparisons were applied between the 6 groups. We rejected the null hypothesis when the $p$-values were $\leq 0.05$, and in such cases the differences were considered significant. If any significant change was observed, the effect size was calculated (omega-squared $\left(\omega^{2}\right)$ for two-way ANOVA and Cohen's $d$ for Tukey HSD) $[38,39]$. Data were plotted as means ( \pm S.D.).

\section{Results}

\subsection{Plasma}

The results of the measurements of $\alpha \mathrm{T}$ concentration from plasma samples are presented in Table 1, 2 and 3, and in Fig. 3a. The applied two-way ANOVA demonstrated significant difference for age $\left(\mathrm{F}=10.55, \mathrm{df}=2, p<0.001, \omega^{2}=0.0276\right)$ but no differences for gender $(\mathrm{F}=0.64, \mathrm{df}=1, p=$ 0.427 ) or age $v s$. gender $(\mathrm{F}=1.11, \mathrm{df}=2, p=0.339)$. Post hoc analysis with Tukey HSD test yielded a significant increase in $\alpha \mathrm{T}$ concentrations with aging only between 16 and 66 weeks old male mice ( $p<0.01$; Table 2), with a 2.234 effect size (Table 3). 


\subsection{Brain regions}

The measurements of $\alpha \mathrm{T}$ concentration from brain samples are demonstrated in Table 1, 2 and 3, and Fig. 3b-f. In light of the validation parameters, both ECD and FLD measurement are applicable for the determination of $\alpha \mathrm{T}$ from brain samples and accordingly, the results of FLD and ECD measurements were averaged for each individual CNS sample. In the next step, the implementation of two-way ANOVA with Tukey HSD post hoc test yielded the following results.

In the striatum (Fig. 3b), there was a significant difference for age $(\mathrm{F}=120.019$, $\mathrm{df}=2, p<0.001$, $\left.\omega^{2}=0.0752\right)$ and gender $\left(\mathrm{F}=23.062, \mathrm{df}=1, p<0.001, \omega^{2}=0.0070\right)$, and for age vs. gender $(\mathrm{F}=$ $3.588, \mathrm{df}=2, p=0.0353, \omega^{2}=0.0016$ ) as well. The Tukey HSD post hoc test revealed significantly elevated $\alpha \mathrm{T}$ concentrations in the latter groups in the following pairwise comparisons from those of a priori decided: $p<0.001$ for 6 vs. 16 weeks old females and $p<0.01$ for males; $p<0.001$ for both 16 vs. 66 weeks old females and males; $p<0.001$ for both 6 vs. 66 weeks old females and males; $p<0.05$ for 16 weeks old males vs. females and $p<0.001$ for 66 weeks old males vs. females (Table 1 and 2).

In the cortex (Fig. 3c), there was also a significant difference for age $(\mathrm{F}=159.589$, df $=2, p<$ $\left.0.001, \omega^{2}=0.1042\right)$, gender $\left(\mathrm{F}=17.377, \mathrm{df}=1, p<0.001, \omega^{2}=0.0054\right)$, and for age $v s$. gender $(\mathrm{F}$ $\left.=5.465, \mathrm{df}=2, p=0.0073, \omega^{2}=0.0029\right)$. The Tukey HSD post hoc test revealed significantly elevated $\alpha \mathrm{T}$ concentrations in the latter groups in the following pairwise comparisons from those of a priori decided: $p<0.001$ for 6 vs. 16 weeks old females and $p<0.05$ for males; $p<0.001$ for both 16 vs. 66 weeks old females and males; $p<0.001$ for both 6 vs. 66 weeks old females and males and $p<0.001$ for 66 weeks old males vs. females (Table 1 and 2).

Furthermore, in the hippocampus (Fig. 3d), similar results were demonstrated for age $(\mathrm{F}=195.500$, df $\left.=2, p<0.001, \omega^{2}=0.1056\right)$, gender $\left(\mathrm{F}=24.343, \mathrm{df}=1, p<0.001, \omega^{2}=0.0063\right)$, and for age vs. gender $\left(\mathrm{F}=7.045\right.$, df $\left.=2, p=0.0021, \omega^{2}=0.0033\right)$. The Tukey HSD post hoc test revealed significantly elevated $\alpha \mathrm{T}$ concentrations in the latter groups in the following pairwise comparisons from those of a priori decided: $p<0.001$ for both 6 vs. 16 weeks old females and males; $p<0.001$ for both 16 vs. 66 weeks old females and males; $p<0.001$ for both 6 vs. 66 weeks old females and males and $p<0.001$ for 66 weeks old males vs. females (Table 1 and 2).

With regard to the cerebellum (Fig. 3e) and the brainstem (Fig. 3f), there was a significant difference for age $\left(\mathrm{F}=17.091, \mathrm{df}=2, p<0.001, \omega^{2}=0.0134\right.$ and $\mathrm{F}=3.491, \mathrm{df}=2, p=0.0384, \omega^{2}=$ 0.0021 , respectively) and gender $\left(\mathrm{F}=10.66, \mathrm{df}=1, p=00020, \omega^{2}=0.0040\right.$ and $\mathrm{F}=13.295, \mathrm{df}=1$, $p<0.001, \omega^{2}=0.0051$, respectively), but not for age vs. gender $(\mathrm{F}=2.897, \mathrm{df}=2, p=0.0649$ and $\mathrm{F}$ $=0.820, \mathrm{df}=2, p=0.4464$, respectively). The Tukey HSD post hoc test revealed significantly elevated $\alpha \mathrm{T}$ concentrations only in case of the cerebellum in the latter groups in the following 
pairwise comparisons from those of a priori decided: $p<0.01$ for 6 vs. 16 weeks old females and $p$ $<0.001$ for 6 vs. 66 weeks old females (Table 1 and 2).

The corresponding effect size values for the significant differences in brain $\alpha \mathrm{T}$ concentrations are presented in Table 3.

\section{Discussion}

Evidence suggests that tocopherols may have a special role in antioxidant protection in lipid-rich structures, such as the CNS. As there is a clear worsening of brain functioning with aging, there were several approaches which aimed at the achievement of neuroprotection via the administration of exogenous $\alpha \mathrm{T}$ [40-44]. However, only limited data are available on the changes of endogenous tocopherol levels either in human or murine brain samples with aging [12, 13, 17, 18, 28]. Therefore, there is a special need for the fine assessment of age-related changes in $\alpha \mathrm{T}$ levels. The identification of clear trends with regard to either certain brain regions or genders may help to understand the differences in the sensitivity to oxidative damage. Although the main focus may be paid on human studies, the assessment of rodents from this point of view may also yield relevant information in light of the fact that most preclinical research on neurodegeneration is carried out in animals belonging to this subfamily.

Accordingly, the aim of the current study was to determine region-, age- and gender-specific changes in brain $\alpha \mathrm{T}$ level in the $\mathrm{C} 57 \mathrm{Bl} / 6$ mouse strain, which is one of the most commonly applied strains in the research on neurodegeneration. Furthermore, our study was supplemented with the assessment of plasma samples as well to be able the judge the possible influence of peripheral changes on brain $\alpha \mathrm{T}$ levels. The results demonstrated that brain $\alpha \mathrm{T}$ levels significantly increased in the striatum, cortex, and hippocampus with aging in both genders. This increase was more pronounced in females and the magnitude of this difference also rose with aging in case of all the above-mentioned brain regions. However, in case of the cerebellum, a moderate elevation could be detected only in females, whereas in case of the brainstem there was no significant change in $\alpha \mathrm{T}$ level. With regard to plasma samples, no clear trend could be identified, a significant difference was found only between 16 and 66 weeks old males. These findings are in line with those found by Takahashi et al. [28] and Gohil et al. [27], i.e., there is a clear elevation of cortical and hippocampal $\alpha \mathrm{T}$ levels, but only a moderate increase in cerebellar $\alpha \mathrm{T}$ level with aging and significantly higher values in females. The novelty of the current study is the presentation of such a pronounced elevation in striatal $\alpha \mathrm{T}$ level, while no change in brainstem $\alpha \mathrm{T}$ level, and furthermore, the first delineation that the difference between genders significantly increases with aging in case of the striatum, cortex and hippocampus. Similar to that found by Takahashi et al., plasma $\alpha \mathrm{T}$ level 
seemingly does not influence the characteristic change in striatal, cortical and hippocampal $\alpha \mathrm{T}$ levels. In addition to the clear and unbiased demonstration of region-, age- and gender-specific changes in mouse brain $\alpha \mathrm{T}$ level via the application of different validated HPLC methods, this article also aims at highlighting the possible underlying factors behind these findings and their hypothetic significance as well.

For better understanding of these results, we looked further into the transport and metabolism of tocopherols. The transport of vitamin $\mathrm{E}$ in the mammalian body is well documented [45-47]. Due to the chemical properties of vitamin E compounds, their circulation is associated with lipoproteins, but their transcellular transport is mediated by carrier proteins [45]. The major forms of vitamin E, $\alpha \mathrm{T}$ and $\gamma \mathrm{T}$ are taken up by diet and absorbed from the small intestine, followed by their transportation to the liver by chylomicrons. In hepatocytes, a special binding protein, $\alpha \mathrm{T}$ transport protein $(\alpha$-TTP), is expressed and has a major role in $\alpha$ T uptake. Studies have shown that $\alpha$-TTP recognizes preferably $\alpha \mathrm{T}$ by its chemical characters [45]. From liver cells, $\alpha \mathrm{T}$ is transferred to the serum by very-low density lipoproteins (VLDL). Following the hydrolysation of VLDL by plasma enzymes to low-density lipoprotein (LDL), it delivers $\alpha \mathrm{T}$ to extrahepatic tissues via the LDL receptor-mediated pathway $[47,48]$.

In the brain the CSF has an important role in micronutrient distribution, including vitamins as well [46]. The transportation of vitamins $B_{1}, B_{3}$ and $E$ from blood to CSF with simple diffusion cannot provide enough concentrations for tissue cells, therefore several specific systems (facilitated diffusion, active sodium-dependent or independent systems, receptor related systems and many other mechanisms) are included as well [46, 49]. Accordingly, it was proposed that brain $\alpha \mathrm{T}$ homeostasis has a strict regulation, but the precise description of the pharmacokinetics of vitamin $\mathrm{E}$ transport into the CSF and brain is not available yet, although some possible mechanisms were previously described in the literature [46].

One of these mechanisms may be connected to the scavenger receptor class B type 1 (SR-B1) [5052], which is responsible for $\alpha \mathrm{T}$ transport across the blood-brain barrier (BBB) by promoting the uptake of HDL-associated $\alpha \mathrm{T}$ in brain capillary endothelial cells (BCEC). Balázs et al. [50] proposed that SR-B1 is located at the caveolae of the apical membrane of BCEC and facilitates the selective uptake of HDL-associated $\alpha$ T by transcytosis across the BBB. In the study of Srivastava et al. [51], C57B1/6 mice were fed with high-cholesterol and high-fat containing diet and their brain SR-B1 expressions consequently increased, although hepatic SR-B1 expression was not influenced. Furthermore, Mardones et al. [52] demonstrated that SR-B1 knock-out $(\mathrm{KO})$ female and male $(\mathrm{n}=$ 3-6, 2 - 4 months old) mice have significantly higher plasma and lower CNS $\alpha \mathrm{T}$ levels, consistent with the postulated role of SR-B1 at the BBB. Surprisingly, the whole brain levels were not 
decreased enough to cause deficiency symptoms. There are no available data on the influence of aging and gender on SR-B1 expression.

The second possible mechanism may be connected to phospholipid transfer protein (PLTP) [53]. PLTP is highly expressed in the choroid plexus (CP) which raises the possibility that PLTP is involved in the transfer of $\alpha \mathrm{T}$ from plasma into the CSF $[54,55]$. In PLTP KO female mice $(\mathrm{n}=6)$ Desrumaux et al. [54] investigated the brain concentration of $\alpha \mathrm{T}$ and found it decreased by $30 \%$ compared to controls and found considerably higher (by 450\%) lipofuscin level, which is the final product of the reaction of lipid peroxide with proteins during oxidative stress. In the substantia nigra. PLTP deficiency also resulted in the accumulation of brain cholesterol derivatives oxidized at position 7 and besides this, Yokota et al. [56] proved that lipofuscin accumulations could disappear with the application of vitamin E dietary supplementation. Similar to SR-B1, there are also no available data on the influence of aging and gender on PLTP expression.

$\alpha$-TTP serves as a third mechanism of $\alpha \mathrm{T}$ transport in the mammalian brain [56]. The presence of this protein is demonstrated in rodent and human brains as well, although the expression level in normal brain tissue is low [57]. In $\alpha$-TTP KO female and male mice ( $n=2-2)$, the plasma and tissue concentrations were less than $0.46 \mu \mathrm{M}$ and $0.23 \mathrm{nmol} / \mathrm{g} \mathrm{ww}$, respectively. Moreover, supplementation with oral vitamin E raised the plasma concentration of these mice close to normal $(\sim 3.4 \mu \mathrm{M})$, but the brain levels increased only with $\sim 20 \%$, however, this small increase in the brain could eliminate the neurological signs [56]. Gohil et al. [27] also investigated $\alpha$-TTP expression in several CNS and liver tissue samples of 5 months old $\alpha$-TTP KO and control mice with the finding that $\alpha$-TTP protein or its mRNA could only be detected from the liver of controls. Later, Takahashi et al. [28] successfully determined $\alpha$-TTP expressions from the cerebrum, hippocampus and cerebellum. However, they utilized only 12-month-old male mice for that purpose, therefore the effect of aging and gender could not be analysed.

Another investigated pathway is in relation with afamin, a member of the albumin super family and may serve as a transport protein involved in $\alpha \mathrm{T}$ homeostasis as well [58]. Afamin is synthesized endogenously by BCEC and assists $\alpha \mathrm{T}$ transport to astrocytoma cells, but to a lesser extent than HDL-mediated transport. The expression of afamin was detected by immunohistochemistry in porcine, mouse and post mortem human brains. It was also demonstrated that afamin level correlates with the concentration of $\alpha \mathrm{T}$ in the CSF, but not with $\alpha \mathrm{T}$ level in the serum [58, 59]. However, there are no available data on the influence of aging and gender on afamin expression.

Although the above-mentioned findings may support the role of SR-B1, PLTP, $\alpha$-TTP and afamin in the transport and regulation of the $\alpha \mathrm{T}$ levels in the CNS, the assessment of the effect of aging and gender on these transport processes warrants further studies. 
Probably the major significance of the current findings is that the elevations of $\alpha \mathrm{T}$ concentrations by aging may serve as to compensate the burden of oxidative stress which increases with aging [12, 43, 60]. Furthermore, the demonstrated gender-related differences, i.e., significantly higher $\alpha \mathrm{T}$ levels in female striatal, cortical and hippocampal brain regions, may at least partially explain the decreased vulnerability of e.g., C57Bl/6 female mice to certain neurotoxins, e.g., 1-methyl-4-phenyl-1,2,3,6tetrahydropyridine [61-64] compared to the male ones.

In light of the fact that there are only limited and contradictory data are available on the changes of human brain tocopherol levels with aging, the human relevance of the current findings cannot be determined at present. However, the results may draw attention to the importance of antioxidant protection against oxidative damage, the extent of which clearly increases with aging. With regard to the effect of gender on age-related pathological alterations, several human studies were published [65-68]. Király et al. [68] demonstrated that male brain ages faster, following the assessment of the volume of cortical and subcortical grey matter, including that of the hippocampus, putamen and caudate nucleus, within the age-range of 21 to 58 years. Although the age range is presumably different, this male preponderance was not reassured in the most common neurodegenerative disorder, AD [69], but was proposed in the second most common neurodegenerative disorder, PD [70]. Nevertheless, the fact that there is not enough human data to be able to determine the extent of the influence of the alterations in tocopherol homeostasis on the pathogenetic process in major agerelated neurodegenerative disorders, warrants further studies.

In conclusion the current study is the first to demonstrate age-dependent gender-specific changes in $\alpha \mathrm{T}$ level in certain brain regions of the $\mathrm{C} 57 \mathrm{Bl} / 6$ mouse strain which finding may explain the increased vulnerability of male $\mathrm{C} 57 \mathrm{Bl} / 6$ mice to certain neurotoxins targeting these regions, but the delineation of possible underlying mechanisms and the demonstration of their human relevance may require future studies. Nevertheless, a deeper insight into this aspect of antioxidant protection may help the development of therapeutic strategies against age-related pathogenetic processes.

\section{Acknowledgements}

The research was supported by GINOP-2.3.2-15-2016-00034 ('Molecular Biological Fundamentals of Neurodegenerative and Immune Diseases: Therapeutic Trials with Kynurenines') and EFOP3.6.1-16-2016-00008 ('Development of intelligent life science technologies, methods, applications and development of innovative processes and services based on the knowledge base of Szeged'). Dénes Zádori was supported by the János Bolyai Research Scholarship of the Hungarian Academy of Sciences. 


\section{Conflict of interest}

The authors declare no conflict of interest. 


\section{References}

1. Hacquebard M, Carpentier YA (2018) Vitamin E: absorption, plasma transport and cell uptake. Curr Opin Clin Nutr Metab Care 8:133-138

2. Eggermont E (2006) Recent advances in vitamin E metabolism and deficiency. Eur J Pediatr 165:429-434. https://doi.org/10.1007/s00431-006-0084-5

3. Szalárdy L, Zádori D, Klivényi P et al (2015) Electron transport disturbances and neurodegeneration: from Albert Szent-Györgyi's concept (Szeged) till novel approaches to boost mitochondrial bioenergetics. Oxid Med Cell Longev epub.:498401. https://doi.org/10.1155/2015/498401

4. Raszewski G, Chwedorowicz R, Chwedorowicz A, Rothenberg KG (2015) Homocysteine, antioxidant vitamins and lipids as biomarkers of neurodegeneration in Alzheimer's disease versus non-Alzheimer's dementia. Ann Agric Environ Med 23:193-196. https://doi.org/10.5604/12321966.1196878

5. Lopes da Silva S, Vellas B, Elemans S et al (2014) Plasma nutrient status of patients with Alzheimer's disease: Systematic review and meta-analysis. Alzheimers Dement 10:485-502. https://doi.org/10.1016/j.jalz.2013.05.1771

6. Yang F, Wolk A, Håkansson N et al (2017) Dietary antioxidants and risk of Parkinson's disease in two population-based cohorts. Mov Disord 32:1631-1636. https://doi.org/10.1002/mds.27120

7. Schuelke M (1993) Ataxia with vitamin E deficiency. In: Adam MP, Ardinger HH, Pagon RA et al (eds) GeneReviews ${ }^{\circledR}$. University of Washington, Seattle, Seattle (WA)

8. Karg E, Klivényi P, Németh I et al (1999) Nonenzymatic antioxidants of blood in multiple sclerosis. J Neurol 246:533-539

9. Karg E, Németh I, Horányi M et al (2000) Diminished blood levels of reduced glutathione and $\alpha$-tocopherol in two triosephosphate isomerase-deficient brothers. Blood Cells Mol Dis 26:91100. https://doi.org/10.1006/bcmd.2000.0280

10. Klivényi P, Karg E, Rózsa C et al (2001) $\alpha$-Tocopherol/lipid ratio in blood is decreased in patients with Leber's hereditary optic neuropathy and asymptomatic carriers of the 11778 
mtDNA mutation. J Neurol Neurosurg Psychiatry 70:359-362.

https://doi.org/10.1136/jnnp.70.3.359

11. Karg E, Klivényi P, Bencsik K et al (2003) Alpha-tocopherol and NADPH in the erythrocytes and plasma of multiple sclerosis patients. Eur Neurol 50:215-219.

https://doi.org/10.1159/000073862

12. Veres G, Szpisjak L, Bajtai A et al (2017) The establishment of tocopherol reference intervals for Hungarian adult population using a validated HPLC method. Biomed Chromatogr 31:e3953. https://doi.org/10.1002/bmc.3953

13. Battisti C, Dotti MT, Manneschi L, Federico A (1994) Increase of serum levels of vitamin E during human aging: Is it a protective factor against death? Arch Gerontol Geriatr 19:13-18. https://doi.org/10.1016/S0167-4943(05)80043-3

14. Rifkind BM, Segal P (1983) Lipid Research Clinics Program Reference Values for Hyperlipidemia and Hypolipidemia. JAMA 250:1869-1872. https://doi.org/10.1001/jama.1983.03340140039025

15. Vatassery GT, Adityanjee, Quach HT et al (2004) Alpha and Gamma Tocopherols in Cerebrospinal Fluid and Serum from Older, Male, Human Subjects. J Am Coll Nutr 23:233238. https://doi.org/10.1080/07315724.2004.10719366

16. Tohgi H, Abe T, Mika N et al (1994) Concentrations of $\alpha$-tocopherol and its quinone derivative in cerebrospinal fluid from patients with vascular dementia of the Binswanger type and Alzheimer type dementia. Neurosci Lett 174:73-76. https://doi.org/10.1016/03043940(94)90122-8

17. Craft N, B Haitema T, M Garnett K et al (2004) Carotenoid, tocopherol, and retinol concentrations in elderly human brain. J Nutr Health Aging 8:156-62

18. Johnson EJ, Vishwanathan R, Johnson MA et al (2013) Relationship between serum and brain carotenoids, $\alpha$-tocopherol, and retinol concentrations and cognitive performance in the oldest old from the Georgia Centenarian Study. J Aging Res epub.:951786. https://doi.org/10.1155/2013/951786

19. Podda M, Weber C, Traber MG et al (1999) Sensitive high-performance liquid chromatography techniques for simultaneous determination of tocopherols, tocotrienols, 
ubiquinols, and ubiquinones in biological samples. In: Methods in Enzymology. Academic Press, pp 330-341

20. Lass A, Forster MJ, Sohal RS (1999) Effects of coenzyme Q10 and $\alpha$-tocopherol administration on their tissue levels in the mouse: elevation of mitochondrial $\alpha$-tocopherol by coenzyme Q10. Free Radic Biol Med 26:1375-1382. https://doi.org/10.1016/S08915849(98)00330-X

21. Reboul E, Trompier D, Moussa M et al (2009) ATP-binding cassette transporter A1 is significantly involved in the intestinal absorption of $\alpha$ - and $\gamma$-tocopherol but not in that of retinyl palmitate in mice. Am J Clin Nutr 89:177-184. https://doi.org/10.3945/ajcn.2008.26559

22. Johnson CH, Slanař O, Krausz KW et al (2012) Novel metabolites and roles for $\alpha$-tocopherol in humans and mice discovered by mass spectrometry-based metabolomics. Am J Clin Nutr 96:818-830. https://doi.org/10.3945/ajen.112.042929

23. Cimadevilla HM, Hevia D, Miar A et al (2015) Development and validation of a single HPLC method for determination of $\alpha$-tocopherol in cell culture and in human or mouse biological samples. Biomed Chromatogr 29:843-852. https://doi.org/10.1002/bmc.3362

24. Jiang Q, Xu T, Huang J et al (2015) Analysis of vitamin E metabolites including carboxychromanols and sulfated derivatives using LC/MS/MS. J Lipid Res 56:2217-2225. https://doi.org/10.1194/jlr.D061663

25. Hagl S, Berressem D, Grewal R et al (2016) Rice bran extract improves mitochondrial dysfunction in brains of aged NMRI mice. Nutr Neurosci 19:1-10. https://doi.org/10.1179/1476830515Y.0000000040

26. Vécsei L, Tajti J, Klivényi P et al (2001) Sodium azide treatment decreases striatal and cortical concentrations of $\alpha$-tocopherol in rats. J Neural Transm 108:273-278. https://doi.org/10.1007/s007020170072

27. Gohil K, Oommen S, Quach HT et al (2008) Mice lacking $\alpha$-tocopherol transfer protein gene have severe $\alpha$-tocopherol deficiency in multiple regions of the central nervous system. Brain Res 1201:167-176. https://doi.org/10.1016/j.brainres.2008.01.044 
28. Takahashi K, Takisawa S, Shimokado K et al (2017) Age-related changes of vitamin E: $\alpha$ tocopherol levels in plasma and various tissues of mice and hepatic $\alpha$-tocopherol transfer protein. Eur J Nutr 56:1317-1327. https://doi.org/10.1007/s00394-016-1182-4

29. Lai JF, Franke AA (2013) Analysis of circulating lipid-phase micronutrients in humans by HPLC: Review and overview of new developments. J Chromatogr B 931:23-41. https://doi.org/10.1016/j.jchromb.2013.04.031

30. Olmedilla B, Granado F, Southon S et al (2001) Serum concentrations of carotenoids and vitamins A, E, and C in control subjects from five European countries. Br J Nutr 85:227-238. https://doi.org/10.1079/BJN2000248

31. Finckh B, Kontush A, Commentz J et al (1995) Monitoring of ubiquinol-10, ubiquinone-10, carotenoids, and tocopherols in neonatal plasma microsamples using high-performance liquid chromatography with coulometric electrochemical detection. Anal Biochem 232:210-216. https://doi.org/10.1006/abio.1995.0009

32. Siluk D, Oliveira RV, Esther-Rodriguez-Rosas M et al (2007) A validated liquid chromatography method for the simultaneous determination of vitamins $\mathrm{A}$ and $\mathrm{E}$ in human plasma. J Pharm Biomed Anal 44:1001-1007. https://doi.org/10.1016/j.jpba.2007.03.033

33. Hall WL, Jeanes YM, Pugh J, Lodge JK (2003) Development of a liquid chromatographic time-of-flight mass spectrometric method for the determination of unlabelled and deuteriumlabelled alpha-tocopherol in blood components. Rapid Commun Mass Spectrom RCM 17:2797-2803. https://doi.org/10.1002/rcm.1263

34. Yuan C, Burgyan M, Bunch DR et al (2014) Fast, simple, and sensitive high-performance liquid chromatography method for measuring vitamins A and E in human blood plasma. J Sep Sci 37:2293-2299. https://doi.org/10.1002/jssc.201301373

35. R Development Core Team. The R Project for Statistical Computing. Text 1-9. R Foundation for Statistical Computing, 2002. Available from: https://www.r-project.org/. Accessed 9 May 2018

36. Dolan JW (2009) Calibration curves, part II: What are the limits? How are the signal-to-noise ratio and imprecision related? LC-GC N Am 27:306-312 
37. United States Pharmacopeia (2003) U.S. Pharmacopeia, 26th revision/National Formulary, $(<1225>)$ Validation of Compendial Methods, 21. Edition. United States Pharmacopeial Convection, Rockville, MD, 2440

38. Sullivan GM, Feinn R (2012) Using effect size - or why the p value is not enough. J Grad Med Educ 4:279-282. https://doi.org/10.4300/JGME-D-12-00156.1

39. Yiğit S, Mendes M (2017) Which effect size measure is appropriate for one-way and two-way ANOVA models? A Monte Carlo simulation study. Revstat - Stat J (In press)

40. Dysken MW, Guarino PD, Vertrees JE et al (2014) Vitamin E and memantine in Alzheimer's disease: Clinical trial methods and baseline data. Alzheimers Dement 10:36-44. https://doi.org/10.1016/j.jalz.2013.01.014

41. Grimm MOW, Mett J, Hartmann T (2016) The impact of vitamin E and other fat-soluble vitamins on Alzheimer's disease. Int J Mol Sci 17:1785. https://doi.org/10.3390/ijms17111785

42. Farina N, Llewellyn D, Isaac MGEKN, Tabet N (2017) Vitamin E for Alzheimer's dementia and mild cognitive impairment. Cochrane Database Syst Rev 4:Art. No.: CD002854. https://doi.org/10.1002/14651858.CD002854.pub5

43. Zádori D, Klivényi P, Plangár I et al (2011) Endogenous neuroprotection in chronic neurodegenerative disorders: with particular regard to the kynurenines. J Cell Mol Med 15:701-717. https://doi.org/10.1111/j.1582-4934.2010.01237.x

44. The Parkinson Study Group (1993) Effects of tocopherol and deprenyl on the progression of disability in early Parkinson's disease. N Engl J Med 328:176-183. https://doi.org/10.1056/NEJM199301213280305

45. Kono N, Arai H (2015) Intracellular transport of fat-soluble vitamins A and E. Traffic 16:1934. https://doi.org/10.1111/tra.12231

46. Spector R, Johanson CE (2007) Vitamin transport and homeostasis in mammalian brain: focus on vitamins B and E. J Neurochem 103:425-438. https://doi.org/10.1111/j.14714159.2007.04773.x

47. Kayden HJ, Traber MG (1993) Absorption, lipoprotein transport, and regulation of plasma concentrations of vitamin E in humans. J Lipid Res 34:343-358 
48. Mardones P, Rigotti A (2004) Cellular mechanisms of vitamin E uptake: relevance in $\alpha$ tocopherol metabolism and potential implications for disease. J Nutr Biochem 15:252-260. https://doi.org/10.1016/j.jnutbio.2004.02.006

49. Spector R (2000) Drug transport in the mammalian central nervous system: multiple complex systems. Pharmacology 60:58-73. https://doi.org/10.1159/000028349

50. Balázs Z, Panzenboeck U, Hammer A et al (2004) Uptake and transport of high - density lipoprotein (HDL) and HDL - associated $\alpha$ - tocopherol by an in vitro blood-brain barrier model. J Neurochem 89:939-950. https://doi.org/10.1111/j.1471-4159.2004.02373.x

51. Srivastava RAK (2003) Scavenger receptor class B type I expression in murine brain and regulation by estrogen and dietary cholesterol. J Neurol Sci 210:11-18. https://doi.org/10.1016/S0022-510X(03)00006-6

52. Mardones P, Strobel P, Miranda S et al (2002) $\alpha$-Tocopherol metabolism is abnormal in scavenger receptor class B type I (SR-BI)-deficient mice. J Nutr 132:443-449. https://doi.org/10.1093/jn/132.3.443

53. Gander R, Eller P, Kaser S et al (2002) Molecular characterization of rabbit phospholipid transfer protein: choroid plexus and ependyma synthesize high levels of phospholipid transfer protein. J Lipid Res 43:636-645

54. Desrumaux C, Risold P-Y, Schroeder H et al (2004) Phospholipid transfer protein (PLTP) deficiency reduces brain vitamin E content and increases anxiety in mice. FASEB J 19:296297. https://doi.org/10.1096/fj.04-2400fje

55. Albers JJ, Vuletic S, Cheung MC (2012) Role of plasma phospholipid transfer protein in lipid and lipoprotein metabolism. Biochim Biophys Acta BBA - Mol Cell Biol Lipids 1821:345357. https://doi.org/10.1016/j.bbalip.2011.06.013

56. Yokota T, Igarashi K, Uchihara T et al (2001) Delayed-onset ataxia in mice lacking $\alpha-$ tocopherol transfer protein: model for neuronal degeneration caused by chronic oxidative stress. Proc Natl Acad Sci U S A 98:15185-15190. https://doi.org/10.1073/pnas.261456098

57. Kaempf-Rotzoll DE, Traber MG, Arai H (2003) Vitamin E and transfer proteins. Curr Opin Lipidol 14:249-254 
58. Kratzer, I, Bernhart, E, Wintersperger, A et al (2008) Afamin is synthesized by cerebrovascular endothelial cells and mediates $\alpha$ - tocopherol transport across an in vitro model of the blood-brain barrier. J Neurochem 108:707-718. https://doi.org/10.1111/j.14714159.2008.05796.x

59. Jerkovic L, Voegele AF, Chwatal S et al (2005) Afamin is a novel human vitamin E-binding glycoprotein characterization and in vitro expression. J Proteome Res 4:889-899. https://doi.org/10.1021/pr0500105

60. Hollán S, Vécsei L, Karg E et al (1998) [Glycolytic enzyme defects and neurodegeneration] (French). C R Seances Soc Biol Fil 192:929-945

61. Antzoulatos E, Jakowec MW, Petzinger GM, Wood RI (2010) Sex differences in motor behavior in the MPTP mouse model of Parkinson's disease. Pharmacol Biochem Behav 95:466-72. https://doi.org/10.1016/j.pbb.2010.03.009

62. Gillies GE, Pienaar IS, Vohra S, Qamhawi Z (2014) Sex differences in Parkinson's disease. Front Neuroendocrinol 35:370-384. https://doi.org/10.1016/j.yfrne.2014.02.002

63. Murray HE, Pillai AV, McArthur SR et al (2003) Dose- and sex-dependent effects of the neurotoxin 6-hydroxydopamine on the nigrostriatal dopaminergic pathway of adult rats: differential actions of estrogen in males and females. Neuroscience 116:213-222. https://doi.org/10.1016/S0306-4522(02)00578-X

64. Skillings EA, Morton AJ (2016) Delayed onset and reduced cognitive deficits through preconditioning with 3-nitropropionic acid is dependent on sex and CAG repeat length in the R6/2 mouse model of Huntington's disease. J Huntingt Dis 5:19-32. https://doi.org/10.3233/JHD-160189

65. Cowell PE, Turetsky BI, Gur RC et al (1994) Sex differences in aging of the human frontal and temporal lobes. J Neurosci 14:4748-4755. https://doi.org/10.1523/JNEUROSCI.14-0804748.1994

66. Murphy DGM, DeCarli C, Mclntosh AR et al (1996) Sex differences in human brain morphometry and metabolism: an in vivo quantitative magnetic resonance imaging and positron emission tomography study on the effect of aging. Arch Gen Psychiatry 53:585-594. https://doi.org/10.1001/archpsyc.1996.01830070031007 
67. Malpetti M, Ballarini T, Presotto L et al (2017) Gender differences in healthy aging and Alzheimer's Dementia: A 18 F-FDG-PET study of brain and cognitive reserve. Hum Brain Mapp 38:4212-4227. https://doi.org/10.1002/hbm.23659

68. Király A, Szabó N, Tóth E et al (2016) Male brain ages faster: the age and gender dependence of subcortical volumes. Brain Imaging Behav 10:901-910. https://doi.org/10.1007/s11682015-9468-3

69. Mielke MM, Vemuri P, Rocca WA (2014) Clinical epidemiology of Alzheimer's disease: assessing sex and gender differences. Clin Epidemiol 6:37-48. https://doi.org/10.2147/CLEP.S37929

70. Moisan F, Kab S, Mohamed F et al (2016) Parkinson disease male-to-female ratios increase with age: French nationwide study and meta-analysis. J Neurol Neurosurg Psychiatry 87:952957. https://doi.org/10.1136/jnnp-2015-312283

\section{Figure captions}

\section{Fig. 1}

Plotted peak areas vs. voltage diagram of $\alpha \mathrm{T}$ and rT. $\alpha T \alpha$-tocopherol; $r T$ rac-tocol.

\section{Fig. 2}

Representative chromatograms of rT and $\alpha \mathrm{T}$. The chromatograms of blank and spiked (with $\mathrm{rT}$ and $\alpha \mathrm{T})$ mouse plasma samples measured with DAD (a) and those of blank and spiked (with rT and $\alpha \mathrm{T}$ ) mouse brain sample homogenizations measured with ECD (b) and FLD (c) are demonstrated. $\alpha T \alpha-$ tocopherol; $D A D$ diode-array detector; $E C D$ electrochemical detector; FLD fluorescence detector; $r T$ rac-tocol.

\section{Fig. 3}

$\alpha \mathrm{T}$ concentration levels in plasma and in different brain regions of mice. We observed significant elevation of $\alpha \mathrm{T}$ levels in the plasma (a), striatum (b), cortex (c), hippocampus (d) and cerebellum (e), but not in the brainstem (f) with aging. To avoid the overcomplication of this figure, the results of statistical comparisons are presented elsewhere (Table 1, 2 and 3), except that for the interaction which may help in the interpretation of the presence or absence of increasing difference between males and females with aging. Data are presented as mean ( \pm S.D. $) ; \mathrm{n}=9 ; \alpha T \alpha$-tocopherol; N.S. not significant. 